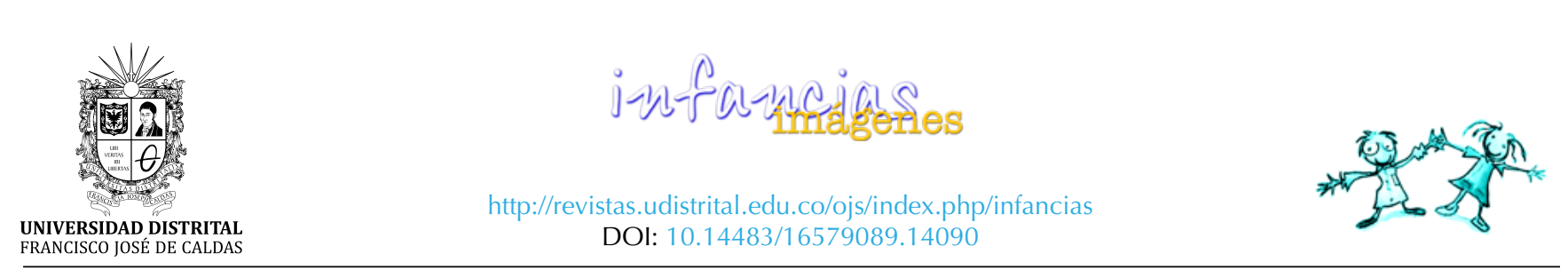

IMÁGENES DE INVESTIGÁCIÓN

\title{
Memoria y construcción de paz con primera infancia y agentes relacionales 2008-2018
}

\author{
Memory and peacebuilding with early child hood \\ and relational agents 2008-2018
}

\author{
Paola Andrea Carmona Toro ${ }^{10}$, Camila Montoya Osorio ${ }^{2}$
}

Para citar este artículo: Carmona, P. A. y Montoya, C.

Recepción: 2019-03-14

Aprobación: 2019-12-05

(2020). Memoria y construcción de paz con primera infancia y agentes relacionales 2008-2018. Infancias Imágenes, 19(1), 46-57

\section{Resumen}

Este artículo de revisión tiene como objetivo presentar temas de reflexión en Colombia sobre memoria historia y construcción de paz en primera infancia y sus agentes relacionales. Es una revisión documental en bases de datos como Redalyc, Scielo, Dialnet, revistas colombianas, libros y memorias de la Bienal Iberoamericana da Niñez y Juventud (2008 al 2018). En los resultados se identificó que los niños y las niñas son sujetos de agencia capaces de participar, tener recuerdos, significarlos en el presente y pensar en el futuro. Las familias y los agentes educativos son fundamentales para la construcción de memoria histórica y de paz; la paz está en la cotidianidad y parte de una polifonía de sucesos, sentires y palabras. Como conclusión: la voz de ellas y ellos tiene que ser legitimada en los procesos de memoria histórica y de construcción de paz, como sujetos con capacidad de agencia y apuestas de país.

Palabras clave: primera infancia, memoria social, paz, familia, profesoras.

\section{Abstract}

The objective of this review article is to present reflection topics in Colombia about memory and peace-building with children in early childhood and their relational agents. Method: documental review in data bases as Redalyc, Scielo, Dialnet, colombian journals, books, and memories of Iberoamerican Biennial of Childhood and Youth, between 2009 and 2018. Results: the children in early childhood are subjects of agency capable of participation, remembrances, and of giving them new meanings in the present to think about the future. Families and educative agents are fundamental for building memory and peace. Peace is in daily and polifonic acts, feelings and words. Conclussion: their voces need to be part of memory and peace-building processes, as subjects with capacity of agency and hopes for the country Keywords: early childhood, collective memory, peace, family, woman teachers.

\footnotetext{
Artículo de revisión, derivado de la investigación "Impactos del potencial de la memoria en los procesos de construcción de paz con participación de la primera infancia y sus agentes relacionales, en la ciudad de Manizales", avalada por la Universidad Católica de Manizales. Investigación iniciada en enero de 2018 y finalizada en noviembre del mismo año.

1 Profesional en Filosofía y Letras, Universidad de Caldas. Especialista en Gerencia Educativa con énfasis en Gestión de Proyectos, Universidad Católica de Manizales. Especialista en Farmacodependencia, Universidad Católica Luis Amigó. Magister en Filosofía, Universidad de Caldas. Candidata a Doctora en Ciencias Sociales, Niñez y Juventud, Alianza Cinde-Universidad de Manizales. Docente investigadora, Universidad Católica Luís Amigó. Grupo de Investigación Jurídicas y Sociales Jurisol. Correo: paola.carmonato@amigo.edu.co

2 Politóloga, Universidad Autónoma de Manizales. Estudiante de Psicología, Universidad Católica Luís Amigó. Auxiliar de investigación de proyecto. Correo electrónico: camila.montoyaos@amigo.edu.co
} 


\section{Introducción}

¿Hasta qué punto es fidedigno nuestro relato de la infancia? ¿Podemos afirmar realmente que conocemos nuestra infancia cuando toda la construcción que tenemos de esta ha sido relatada en tercera persona, y no somos capaces de verificar realmente tal o cual cosa? ¿Podemos fiarnos del relato que nos narran sobre nuestra propia vida aquellos que la viven desde fuera, como espectadores? (Medina, 2016)

La memoria histórica es la posibilidad de pensar el qué, el cómo, el para qué del pasado y su incidencia en la configuración del presente. En este sentido, reconstruir experiencias personales y sociales del pasado (Errazkin y Martínez, 2012) para el caso de la primera infancia y sus agentes relacionales es la posibilidad de dar cuenta de aquello que ha acontecido, cómo se instaura en el presente y las posibilidades de orintación a futuro que desde ellas y ellos se gestan (Ospina-Alvarado, 2018). La memoria implica comprender que la vida es un entramado histórico desde el cual se configura el presente y el futuro (Ricoeur, 1999; CNMH, 2016).

A su vez, la construcción de paz es entendida como el tránsito de la idea de paz general a gestar una nueva forma de entender micro y macro relaciones por fuera de contextos de violencia y desde el trabajo con todos los miembros de la sociedad (Grasa et al., 2019). Por ejemplo, la construcción de paz es posible desde los lenguajes, la interacción y los potenciales de acción de las niñas y los niños (Ospina-Alvarado et al., 2014); así como desde los emprendimientos territoriales, las propuestas pedagógicas e investigativas, las políticas públicas y las acciones colectivas que se gestan desde diferentes organizaciones sociales (Salazar-Castilla et al., 2018)

\section{Metodología}

Para el proceso de revisión documental se consultaron diferentes artículos de reflexión e investigación de carácter cualitativo, en bases de datos como: Redalyc, Scielo y Dialnet; revistas colombianas; libros; y las memorias la Bienal Iberoamericana de Niñez y Juventud. La información fue organizada en una matriz categorial que contenía temas comunes (categorías como memoria y paz; y subtemas como primera infancia, familias y agentes educativos). Este artículo de revisión descriptivo tiene como objetivo presentar al lector temas de reflexión sobre memoria histórica y construcción de paz en primera infancia, familias y agentes educativos. Fueron seleccionados 50 documentos, cuya publicación se dio entre los años 2008 al 2018.

\section{Resultados}

Memoria y construcción de paz: niñas y niños de primera infancia

Tradicionalmente se han desconocido los potenciales de participación, creación, imaginación y narración que tienen las niñas y niños y se leen solo como acompañantes de quienes han sido víctimas de la violencia (padres, hermanos, tíos, entre otro), pero no como sujetos afectados directamente (De la Rosa-González, 2015; Centro Nacional de Memoria Histórica y Caja de Compensación Familiar Compensar, 2017; Ospina et al., 2016). Sin embargo, ellas y ellos tienen autonomía y capacidad de participar de la historia, por eso sus voces y experiencias deben ser escuchadas (Carmona-Parra y Serna, 2018; Gómez et al., 2014; Mejía y González, 2009); no como acción pasiva limitada a la escucha, sino como posibilidad de trasformación de las situaciones que viven diariamente.

Tal es el caso de las zonas que han sido catalogadas como territorios afectados por el conflicto armado colombiano, donde se promueve una subjetividad política que tiende a procesos de reconciliación, paz y participación (Carmona-Parra y Serna, 2018). Desde allí son cogestores de su propio desarrollo, capaces de construir conocimiento y apuestas de paz frente a sí mismos, sus territorios, sus familias y su comunidad (CNMH, 2016). En Colombia, ser niña y niño, es decir, ser un potencial constructor social, ha tenido dos impactos; el primero se constituye en un factor de riesgo para el reclutamiento forzado por parte de los grupos al margen de la ley; el segundo en una potencia, en tanto agente de prevención de hechos violentos, a través del despliegue de su capacidad tranformadora de escenarios latentemente violentos a 
escenarios de construcción de paz. Esto no quiere decir que la capacidad de estar en uno o en otro grupo sea una elección consciente de los niños y niñas; ya que, por ejemplo, ningún niño que va a la guerra elige estar allí, como un adulto (no forzado) si pudiera hacerlo (Alvarado et al., 2014).

En este sentido, los niños no deben pensarse como perpetuadores de una cadena de eventos pasados, ni como seres que tienden a la pureza o a la maldad, sino como sujetos políticos, capaces de edificar procesos de paz y sostenerlos en el tiempo (Alvarado et al., 2014). De ahí la importancia de generar programas, políticas públicas facilitadoras y promotoras de la participación de la primera infancia en procesos familiares, comunitarios y educativos (Mejía y González, 2009).

Políticas a partir de las su voz sea escuchada desde dos vertientes. Una como derecho a la verdad que tienen todas las víctimas y las personas de conocer lo que ocurrió durante el conflicto armado, manifiesto en la Ley de Víctimas (Ministerio de Justicia, 2012); la otra, como la capacidad para recordar, como posibilidad de ir al pasado, rememorar, traer una imagen al presente, a través del recuerdo y resignificar lo ocurrido (Ricoeur, 1999).

La memoria como práctica y como representación se encuentra condicionada por la vivencia, narrable a través del lenguaje, el juego, el arte y de otras formas aparentemente paradadógicas como el olvido, el lenguaje de lo inconsciente y el silencio. Desde cualquiera de estas formas de enunciacón ella implica reconstruir el pasado en el presente y el empoderamiento de la propia historia (Díaz, 2009).

De esta forma, preguntarse por los niños y niñas que han estado vinculados a procesos de violencia es preguntarse por los afectos que ellos cargaron a ese vínculo, por la memoria instalada en esta relación, por su relación con la norma, por cómo se siente con el otro y frente a otro, cómo piensan y sienten ante la diferencia, ¿cómo actúa el niño?, ¿qué efecto lograron estas lógicas instauradas al interior de sus vivencias?, ¿qué efectos en su yo se evidencian? (Díaz, 2009).

Los seres humanos se ven atravesados por multiplicidad de situaciones que marcan, en cierta medida, sus formas de habitar el presente. Esta situación no es propia solo de la adultez, los niños desde sus primeros años de vida también conservan recuerdos que determinan sus maneras de estar en el presente (Ortega y Ruetti, 2014). Al igual que determinan sus procesos relacionales en las instituciones educativas, en la familia, la sociedad y la comunidad, donde el sentido de lo vivido, su significado, se construye a partir del colectivo y los procesos relacionales (Gómez et al., 2014; Sarmiento-Álvarez, 2015).

Las familias, mediante el amor y la confianza, influyen en la forma como ellos recordarán el mundo y cómo se relacionarán socialmente. Por ejemplo, los niños cuyas familias han sido desplazadas o víctimas de la violencia suelen tener más silencios que quienes no han vivido en estos contextos; quienes presenciaron situaciones como masacres sienten miedo, evitan narrar lo ocurrido o incluso relacionarse con personas que rememoren los hechos. Para algunos el juego y la diversión están en el pasado porque en el presente no quieren hacer uso de ellos.

Por otro lado, las niñas y los niños no están aislados de las vivencias de sus padres (Mejía y González, 2009; De la Rosa-González, 2015; López-Arboleda, 2013; Centro Nacional de Memoria Histórica y Caja de Compensación Familiar Compensar, 2017).

Este último aspecto representa una dicotomía de la memoria:

Un estudio del investigador Florentino Moreno sobre la Niñez y el conflicto armado en Centroamérica, recogió a dos poblaciones de niños, un grupo que creció en la guerra entre Nicaragua y el Salvador, y otro grupo que creció en la España democrática franquista. El resultado concluyó que no existe una relación causa efecto entre un contexto violento y una socialización bélica y un contexto pacífico y una socialización favorable a la paz. En ambos grupos hubo niños con actitudes guerreristas y pacifistas. (Alvarado et al., 2014, p. 55)

El resultado del estudio supone a los adultos como los principales responsables de situar a las niñas y los niños en los conceptos de "inocentes", "pueriles" e "incapacitados para tomar decisiones". Sin embargo, quienes habitan el conflicto en 
cualquiera de sus manifestaciones, no están "poseídos por el pasado" y pueden construir desde sus memorias violentas o no nuevos mundos de significantes o significados para dotar de sentido su vida. Así, las niñas y los niños de primera infancia sí tienen recuerdos del mundo - lugares, sabores, olores, formas, eventos-y de sí mismos —emociones, sentimientos - referidos a las preguntas clásicas por el qué, dónde y el cómo de la memoria (Ortega y Ruetti, 2014).

Dichos recuerdos son comunicados a través del lenguaje, de forma narrativa. Así, entre mayor es la capacidad de los niños para codificar sus recuerdos en un esquema lingüístico, mayor es la posibilidad de comunicación de aquello que recuerdan, teniendo la capacidad para contar sus vivencias (Ortega y Ruetti, 2014; CNMH, 2016) y las que les han sido transmitidas por los mayores. El lenguaje, a su vez, permite la deconstrucción de los sentidos hegemónicos que a lo largo de la historia se han presentado en la construcción del pasado y que desde la voz de los niños pueden crear mundos posibles, narrándose, narrando a otros y escuchando (Gómez et al., 2014; CNMH, 2016; Sarmiento-Álvarez, 2015; Alvarado et al., 2012; Centro Nacional de Memoria Histórica y Caja de Compensación Familiar Compensar, 2017); todo ello procurando encontrar otras formas de habitar el presente y la realidad.

Las niñas y los niños han construido parte de su historia de vida a través, de la oralidad, de los relatos que le han sido narrados por sus familiares y comunidad (Manrique-Suárez, 2014). Esto significa que no se encuentran aislados de las potencias narrativas de las comunidades, a la vez que esas prácticas narrativas cobran sentido en tanto están inmersas en una temporalidad y una espacialidad (Alvarado et al., 2012; Ospina-Alvarado et al., 2013). Ellas y ellos pueden ser narradores de su historia y de las historias que les han sido contadas, a través de lenguajes generativos (Ospina-Alvarado et al., 2013).

La narración también tiene sentido de sanación y denuncia frente a lo que han vivido y a la manera como la sociedad responde a sus vivencias, es una suerte de "poder develatorio" (Alvarado et al., 2012), que rompe con el esquema de aquello que puede ser enunciado por los niños y las niñas, como el caso de la violencia frente a la condición de lo humano que los ha afectado en el pasado y los sigue afectando en el presente. Este proceso es sanador, en tanto comunicar lleva a pensar qué se hizo, cómo se participó y qué se puede hacer en el ahora.

Otro aspecto que cabe mencionar, encontrado en los documentos revisados, es la incidencia de los factores emocionales en los recuerdos que las niñas y los niños tienen. Ya que desde sus primeros años de vida entablan relaciones sociales y afectivas con quienes los rodean y, además, tiene gran incidencia en ellos las vivencias familiares (Ortega y Ruetti, 2014; Mejía y González, 2009; López-Arboleda, 2013). Esto se evidencia cuando atraviesan por situaciones de tristeza, en las que sus recuerdos suelen estar cargados de evocaciones tristes o angustiadas. Caso contrario a lo que ocurre cuando sus estados emocionales están vinculados a la alegría: los recuerdos suelen evocar en mayor medida sucesos que les generaron diversión, alegría, tranquilidad, risas, entre otras.

La enunciación del dolor evoca lo que pasó en sus vidas (Gómez et al., 2014), el miedo, la falta de seguridad, el temor, la falta de futuro, los sentimientos de venganza, la culpa (Ospina-Alvarado et al., 2013). Las narrativas dan cuenta de las cicatrices, las carencias, la ausencia de oportunidades y la precariedad (Quintero et al., 2013) de la que hacen parte. Vale la pena preguntar: ¿de qué contenidos se dota el presente de los niños? Por ejemplo, cuando han estado inmersos en contextos de conflicto armado desde sus múltiples formas de violencias: desaparición forzada, asesinatos, masacre e intimidación a los adultos por parte de grupos armados. Es decir, ¿cómo estas situaciones afectan sus formas de estar en el ahora y la forma como ellos comprenden, asimilan, y reconstruyen tales situaciones de afectación en el presente? (Mejía y González, 2009). Las memorias del dolor ponen de manifesto la manera como las formas de relacionamiento trastocan y afectan la construcción de identidad invidual y colectiva $(\mathrm{CNMH}, 2017)$.

Al respecto, Alvarado et al. (2014) presentan cómo algunas niñas y niños desvinculados de grupos armados ilegales, que durante su permanencia 
en los grupos armados se implicaron más profundamente que los demás en las acciones de guerra, se comprometen de manera más decidida y entusiasta con sus procesos de reinserción a la vida civil y logran, después de varios años, procesos exitosos y ejemplares.

Metodologías para el abordaje de la memoria y la construcción de paz

En cuanto a la metodología para el trabajo de memoria histórica con niñas y niños de primera infancia se ha identificado que el juego y el arte son los más empleados. Pero, con el llamado de atención a que sea una ruta transitada con atención y preparación previa, durante y posterior a cada encuentro; teniendo presente, además, que las actividades que se propongan deben ser adaptadas a las características de los grupos poblacionales con los que se trabaje (Centro Nacional de Memoria Histórica y Caja de Compensación Familiar Compensar, 2017).

En algunos contextos marcados por la violencia o donde las niñas y los niños fueron víctimas directas, se evidencia cierta reproducción de lo observado o vivido. Por ejemplo, en instituciones educativas que albergaban personas en situación de desplazamiento era común encontrar juegos cuyos roles estaban entre ser miembro de la Policía, Ejército, paramilitar o guerrillero, que tenían como intención atacar al otro, en un acto de imitación de las realidades que vivieron en sus territorios (Mejía y González, 2009).

Esta situación no es una constante, por el contrario, el juego es dinamizador para la evocación de la memoria; mediante experiencias, sensaciones, olores, colores, formas y posibilidades creativas para narrar. El juego es una forma de nombrar lo innombrable, lo impronunciable, ya que permite volver al pasado sin temor al castigo, a las miradas; al tiempo que permite el involucramiento de las niñas y los niños en diferentes actividades porque se torna vivencial (De la Rosa-González, 2015; CNMH, 2016).

El juego también brinda la posibilidad de entrar en diálogo con otros mediante una apuesta empática, conociendo, sintiendo y comprendiendo experiencias vividas quienes fueron afectados por el conflicto armado colombiano (Centro Nacional de Memoria Histórica y Caja de Compensación Familiar Compensar, 2017).

Palermo (2009) hace una revisión de autores que consideran como posibilidad analítica las memorias de juegos y los juguetes en la infancia. Para Benjamin:

[...] articular históricamente el pasado no significa conocerlo tal como verdaderamente fue. Significa apoderarse de un recuerdo, atrapar imágenes del pasado tal como se aprecian en el sujeto cuando la amenaza es la posibilidad misma de desaparición del pasado en el presente. (p. 157)

Por su parte, para Agamben (1978) "se debe reconocer la infancia como transformación de la lengua en discurso y de la naturaleza en historia, ya que la infancia es la dimensión originaria de lo humano que se funda en el lenguaje" (p. 158). Mientras que, para Larrosa, es indispensable reconocer al niño como otro, cuya experiencia debe ser escuchada desde su propia voz; es decir, hay que potenciar su voz.

Al igual que el juego, el arte también se considera una herramienta fundamental para los trabajos de memoria, de recuperación de recuerdos, para procesos de resignificación, expresión de sentimientos, creación, recreación del pasado, sanación y como una forma estética de involucramiento con la realidad (De la Rosa-González, 2015; Parra-Ospina, 2014). Por ejemplo, niñas y niños desplazados por la violencia en Colombia y refugiados en Ecuador han encontrado en el dibujo una forma de narrar el pasado y contar lo sucedido (UNHCR, 2013). Los archivos sonoros también posibilitan la trasmisión de realidades desde el diálogo con la imaginación, como el caso de la apuesta La historia de los colibríes y las langostas (CNMH, 2016), la cual mediante 10 audio-historias se narra el rechazo a la guerra y las puestas de construcción de paz de varias niñas y niños desde sus territorios; "Un canto pa' no olvidar a la niñez de Colombia" es un trabajo de memoria histórica sobre el cuidado y responsabilidad que tenemos todas y todos los colombianos con la niñez de nuestro país (CNMH, 2018). La pintura a través de "Personitas de colores", concurso de 
pintura en la ciudad de Medellín, busca conocer los sueños, recuerdos, deseos e intereses de las niñas y los niños (Montoya-Ramírez y Zuluaga-Arias, 2014). Al igual que la construcción del árbol genealógico como actividad para que las niñas y niños conozcan su historia y el sentido que ellas tienen (CNMH, 2016). El teatro se convierte en otra posibilidad para trabajar memoria; la obra de teatro Camino a casa fue creada para narrar la desaparición forzada, en lengueje y contenido apto para niñas y niños (CNMH, 2014). El cuento Un largo camino permite evocar los recuerdos, la imaginación y las emociones (Vallejo-Franco, 2018; CNMH, 2018).

El arte es un "vehículo conector del pasado con el presente" (De la Rosa-González, 2015, p. 325) que desde sus lenguajes propios propende por la memoria, la reconfiguarción de relaciones desde la solidaridad, el reconocimiento y la participación (Centro Nacional de Memoria Histórica y Caja de Compensación Familiar Compensar, 2017). También es proyección a futuro, mediante la articulación entre el pasado — recuerdos-, el presente —realidad del ahora - y el futuro - proyecciones de vida- (Ospina-Ramírez y Ospina-Alvarado, 2017; Alvarado et al., 2012).

La metodología, técnicas e instrumentos utilizados para los trabajos de memoria histórica deben estar trasversalizados por un enfoque diferencial (Sarmiento-Álvarez, 2015); aspecto replicable también en los procesos de construcción de paz y los educativos (Córdoba, et al., 2016). Es decir, el enfoque para primera infancia debe ser diferente al enfoque de jóvenes, adultos y adultos mayores, de tal manera que permita conocer las afectaciones, reflexiones y formas de resisitir que las niñas y niños tiene frente a sucesos que han impactado su vida. La historia ha sido generalmente contada desde la voz de los adultos (Sarmiento-Álvarez, 2015), por ello es necesario que los recuerdos y los relatos de la primera infancia sean legitimados e incorporados a las memorias sociales como lo son los de otros grupos etáreos (CNMH, 2016).

Para finalizar, la memoria histórica de las niñas y los niños no debe ser solo de suscesos tristes, referida al dolor o a los daños morales a los que se han visto expuestos y cuyos relatos tienen como finalidad "poner al descubierto la crueldad humana, el grado de precariedad, el malestar y dolor en la vida comunitaria" (Quintero et al., 2013, p. 86), pese a ser un aspecto muy importante a tener en cuenta en los procesos de memoria histórica, también está la exigencia de ser una memoria de todo aquello que para ellos es significativo, como las luchas de sus padres, las fortalezas comunitarias y barriales, las experiencias de vida compartidas con los compañeros de clase. En otras palabras, no es solo una memoria victimizante, sino de las potencias (Sarmiento-Álvarez, 2015), porque la memoria es un proceso que contribuye al reconocimiento de sí mismo y del otro (Ricoeur, 1999).

\section{Construcción de paz}

"La construcción de la paz en nuestro país implica el entendimiento previo y el diálogo posterior entre los sentidos que personas y comunidades atribuyen al drama vivido por generaciones enteras de colombianos, incluidas la niñez y la adolescencia" (Sarmiento-Álvarez, 2015, p. 150). Las niñas y los niños son agentes constructores de paz, con capacidad para gestarla desde sus territorios (Gutiérrez-Rodríguez et al., 2016) y desde sus potenciales: lúdico, afectivo, moral, político, creativo para la resolución de conflictos (Ospina-Ramírez y Ospina-Alvarado, 2017), de la memoria, porque "las experiencias de construcción de paz, desde una perspectiva de memoria, son la vida que re-nace" (Jiménez-Ossa y Luna-Carmona, 2018, p. 113). Los potenciales son recursos con los que cuentan para afrontar diferentes situaciones que se presentan en su cotidianidad; estos permiten la construcción de paz en sus contextos y facilitan posibilidades futuras.

El potencial afectivo hace referencia al autoconcepto y autoestima; cómo a partir de reconocerse a sí mismos las y los niños son capaces de reconocer al otro y a lo otro, de tal forma que sus maneras de relacionamiento sean desde el amor y no desde la violencia. El potencial comunicativo es la forma dialógica con los otros y el reconocimiento de sí mismo como interlocutores válidos, capaces de trasformar sus contextos de violencia en espacios de paz a través de las palabras.

El potencial ético-moral es entendido desde la perspectiva de cuidado del otro, respeto, reflexión 
axiológica y ampliación del círculo ético de las niñas, niños, familias y agentes educativos. Mientras que el potencial político es la posibilidad de afectación de la realidad desde una postura crítica, la capacidad de trasformación como agentes de cambio. El potencial creativo para la trasformación de conflictos son los recursos que tiene para encontrar caminos, nuevas formas de actuar y otras formas de relacionarse (Ospina-Ramírez y Ospina-Alvarado, 2017).

Cuando las niñas, los niños y las familias narran de forma distinta situaciones de violencia, desde su potencial creativo que tiene para transformarlas, la agencia se hace mucho más visible para la construcción de paz, porque son capaces de generar soluciones desde sus propias vivencias y perspectivas de contexto (Ospina-Ramírez y Ospina-Alvarado, 2017; Sarmiento-Álvarez, 2015). Desde la estrategia "Generación de paz" se reconoce la capacidad de participación y transformación de los niños hacia contextos de paz, a través de preguntas como ¿cómo proponen ustedes que se debe realizar la paz?; res52 puestas consignadas en manifiestos encaminados a visibilizar sus voces y apuestas de paz (Alta Consejería para los Derechos de las Víctimas, 2015).

La paz no se relaciona solo con el conflicto armado; por el contratario, existe multiplicidad de formas de vivir la paz o las paces (Ospina-Alvarado et al., 2018; Parra-Ospina, 2014), como evitar pelear con los amigos y compañeros, perdonar a quien los daña, jugar más, que no se presente maltrato físico del padre hacia la madre, amar, querer y respetar a la Polícia, entre otras. La paz es una polifonía de pensamientos, sientimientos y vivencias que tiene las niñas y los niños (Naranjo-Moreno, 2015). La paz también es poesía, palabra, sueños, magia, naturaleza, corazón, amor y es poema que cuenta la vida (Rodas, 2016).

\section{Familias}

Las familias con sus posibilidades relacionales se constituyen como el eje central para el desarrollo y reconfiguración del presente de las niñas y los niños (Ospina-Alvarado, 2018), dada la capacidad para restaurar emocionalmente los sucesos del pasado, en especial cuando los recuerdos son de situaciones dolorosas o de ruptura de contexto vital
(Mejía y González, 2009; Ospina-Alvarado et al., 2018, Arias-Vanegas, 2016); esto desde papel como adultos presentes en las vidas de las niñas y los niños (Carmona-Parra y Serna, 2018). Para el caso del conflicto armado es fundamental el acompañamiento familiar en los procesos de duelo, encaminado a tener memorias que trasciendan el dolor $y$ permitan la re-existencia.

El trabajo con familias en procesos de memoria histórica aporta a las niñas y niños en cuanto la trasmisión identitaria, cultural y de tradiciones, por lo general, a través de la oralidad y la narración de historias por parte de los padres a sus hijos (De la Rosa-González, 2015), suele ser memoria generacional transmitida por miembros mayores del núcleo familiar a los más jóvenes. Estas formas de comunicación de los recuerdos, requiere ser contada de tal manera que tanto las niñas y niños como las familias se conecten con lo que ocurrió.

El arte y el juego también constituyen una herramienta indispensable para el trabajo con familias y la modificación de los sistemas relacionales, en especial cuando estas han sido afectadas por el conflicto armado colombiano o por violencia al interior del hogar, que se naturaliza en las formas de relacionamiento de las niñas y los niños con su entorno (Gómez et al., 2014).

Las familias también son constructoras y co-constructoras de cultura de paz en las niñas y niños, esto desde las prácticas cotidianas en los hogares y desde la manera como ellas repercuten en la forma de habitar la escuela; lo que incide en las subjetividades, en el caráter formativo y en el carácter constructivo como ciudadano (Rodríguez-Bustamante, et al., 2017). La cultura de paz que se gesta en sus espacios vitales y como vinculo posible en el aula de paz (Rodríguez-Bustamante et al., 2017).

Agentes educativos y maestras

Las niñas y niños pasan gran parte del día en los Centros de Desarrollo Infantíl (CDI) o en las institciones educativas (escuelas), allí están en relación directa con agentes educativas y maestras; situación que guarda relación importante con los recuerdos de las niñas y los niños frente sobre las vivencias 
en la escuela. En este sentido, las formas de relacionamiento entre maestras, agentes educativas y las niñas y niños pueden por ejemplo, contribuir a romper las lógicas de violencia, sentimientos de venganza, miedo, entre otros situaciones presentes en en aula de clase (Gómez et al., 2014).

Las agentes educativas y maestras se convierten en los procesos de construcción de las memorias en figura de acompañamiento, seguridad, confianza, protección y que reconfortan a las niñas y los niños (De la Rosa-González, 2015; Ospina-Alvarado, 2018), al tiempo que aportan en la construcción de sujetos capaces de leer su vida desde diferentes ópticas, encaminadas a reconocer el pasado, significar el presente y crear escenarios para el futuro (Manrique-Suárez, 2014). Desde la psicología educativa los niños aprenden a resolver conflictos en la escuela y en la formación preescolar a partir de los 5 años, edad en la que se entienden los sistemas de gratificación y recompensa; mientras que a los 9 años aflora la empatía. Al respecto, Valderrama (2001) plantea que ciertos docentes tienen la visión de que el estudiante, en relación con el conflicto, posee un estatuto de minoría de edad. Pues, según estos docentes, los estudiantes carecen de criterio para fijar posiciones frente a los problemas y conflictos que se presentan a nivel institucional o estamental, por lo cual no deben ser llevados para afrontarlos conjuntamente. Esto genera que el conflicto se vea como una gran disfunción en el individuo y no como una realidad histórica desde la que se pueda construir una base de discusión y se puedan tejer caminos de paz.

Los maestros también son constructores de paz con la responsabilidad de entretejer discursos de paz, desarmar la sociedad, la dureza mental y abrazando la palabra en el aula (Pineda-Muñoz, 2016). Aula que debe ser siempre democrática, pensada para el concenso, la discución y la mediación; esto, si realmente se quiere educar para la paz y en la paz "porque de lo contrario seguiremos pintando en el suelo palomas que se borrarán con el tiempo" (Giraldo-Hoyos, 2016, p. 100).

Gómez-Esteban (2009) conceptualiza al respecto que la única forma de hacer memoria en la escuela es caracterizando los modos de subjetivación política de la siguiente manera: “a) subjetivación a través del cuerpo; b) subjetivación a través de la norma; c) subjetivación a través del saber, d) subjetivación a través de la alteridad" (p. 146). En otras palabras, se hace memoria en la escuela cuando el niño o la niña: entiende que el lugar de la memoria es el cuerpo, comprende que en la relación con otros hay reglas, se interesa por el aprendizaje y comprende al otro desde su ser.

Respecto a las experiencias significativas de la creación de memoria en la escuela, Becerra et al. (2012) han recopilado algunos casos en latinoamérica, a saber:

1. Renán Vega Cantor, quien a finales de la década de 1990 en la Universidad Pedagógica Nacional se acercó a docentes en ejercicio con el fin de trabajar la fuente oral con los estudiantes y su relación con la historia local. De allí nació el libro ¡Déjenos hablar!

2. En un segundo libro, Historia: conocimiento y enseñanza. La cultura popular y la historia oral en el medio escolar, Renán Vega aborda elementos de gran envergadura para el maestro en ejercicio, como la tradición oral, la historia de vida, la historia oral y las tipologías de historia oral que se podrían trabajar en la escuela.

3. Investigaciones de Fabio Castro Bueno, docente de la Secretaria de Educación (SED), quien participa en la conformación, para el año 2005, del Centro de Memoria en Educación y Pedagogía del IDEP en la ciudad de Bogotá.

4. Por otro lado, en la Universidad Distrital Francisco José de Caldas de Bogotá se gestan investigaciones sobre el papel de la narrativa infantil como una herramienta por medio de la cual se organiza la experiencia y se materializa la memoria.

5. Bajo la perspectiva de los principios del pensamiento narrativo y la experiencia, los investigadores Absalón Jiménez Becerra y Raúl Infante Acevedo abordan el tema de las narrativas infantiles en Bogotá, con un grupo de niños en situación de exclusión social, ubicados en un rango de edad entre los 8 y 14 años, cuyo interés es rescatar su experiencia y noción de ciudad (Jiménez e Infante, 2008).

6. Ambos autores escriben el artículo "Memoria, historia y escuela" (2008), con el interés de dar cuenta de cómo el tema de la memoria para la escuela y los docentes se presenta con un doble 
perfil de preocupación: uno de carácter pedagógico y otro de carácter político.

Todas estas estrategias implican que, históricamente en Colombia, se han realizado esfuerzos importantes por hacer memoria. De hecho, la reglamentación escolar sobre la enseñanza de la violencia política, aunque reciente, ha impactado de manera positiva las aulas de clase con asignaturas como competencias ciudadanas, política y economía nacional, historia de la violencia y, por supuesto, la cátedra de la paz que incluye asignaturas como educación para la paz, entre otras (Gómez, 2016). Cabe mencionar que se están aplicando directamente a la educación básica, pero la preescolar se ha quedado por fuera. De allí la pertinencia de empezar a hablar de memoria en primera infancia.

Esto muestra que la memoria actúa como un todo simbólico que, aunque no ha sido reconocido como un área de abordaje de nuestra historia en los currículos escolares, tiene gran importancia en la cultura del sujeto crítico y responsable políticamente de sus vivencias como ser social.

\section{Conclusiones}

Las diferentes fuentes documentales consultadas, que datan desde el año 2008 hasta el 2018, escritas y pensadas para el contexto colombiano permiten dar cuenta de aspectos en común frente a las reflexiones sobre procesos de reconstrucción de la memoria histórica y construcción de paz con primera infancia y sus agentes relacionales. Así, se encuentran los siguientes ejes articuladores:

La memoria histórica es entendida por la mayoría de los autores como la posibilidad que tienen las niñas, los niños, las familias y los agentes educativos para resignificar el pasado en el presente mediante recuerdos. Estos recuerdos pueden estar vinculados al dolor o a la alegría; para el caso de recuerdos dolorosos es fundamental el acompañamiento de los agentes relacionales en los procesos de duelo, en pro de la sanación y su resignificación. Mientras que los recuerdos alegres son una evocación a la resistencia, a la vida y al estar con otros.

Los procesos de memoria histórica deben incluir la voz de las niñas y los niños de primera infancia, desde la manera como los ha impactado el pasado, los sentidos que le otorgan y las implicaciones a presente y futuro que desde sus vivencias tienen los sucesos; desde esta perspectiva, son interlocutores válidos para narrar la historia del país. A partir de lo cual resulta importante formular la pregunta: ¿qué tipo de pasado queremos que ellas y ellos recuerden?; ¿qué sucesos, qué experiencias, en compañía de quién recordarán?

Las memorias generacionales son muy importantes, por eso la estrecha relación que se evidencia entre los procesos de reconstrucción de la memoria histórica, los vínculos familiares y los vínculos educativos para la configuración de aquello que las niñas y los niños recuerdan. El recuerdo de la infancia se vuelve entonces un acto inspirado por la confianza en el otro.

También, es importante comprender que poder narrar el pasado y hacer procesos de construcción de memoria se encuentra estrechamente relacionado con la garantía de sus derechos, al cuidado, el amor, la subsistencia, territorios sanos, salud, educación, juego, la recreación y participación.

A nivel metodológico es fundamental proponer estrategias diferenciales y situadas que respondan a los contextos, edades, poblaciones, entre otros aspectos. Para lo cual, el arte y el juego son dos herramientas de gran apoyo.

Con relación a la construcción de paz, las niñas y los niños no conciben la paz como un documento institucionalizado o como acuerdos con grupos armados para la finalización de un conflicto. Para ellas y ellos la paz es una polifonía de sonidos, de vivencias que pueden hacer parte de su resignificación del pasado, pero que también puede ser parte de la vida cotidiana. Construir paz está atravesado por las palabras, los poemas, los dibujos, las acciones, las relaciones con el otro y con lo otro. Para estos procesos, tanto la familia, como los agentes educativos o maestros tiene una función preponderante como generadores de cultura de paz, en los hogares y en el aula de clase, desde el ejemplo, desde el amor, la confianza; pero, sobre todo desde el reconociendo de las potencias de las niñas y los niños para participar activamente en la construcción de país. 


\section{Referencias}

Agamben, G. (1978). Infancia e historia. Ensayo sobre la destrucción de la experiencia. https://www.usfx.bo/ nueva/vicerrectorado/citas/SOCIALES_8/Historia/ Giorgio\%20Agamben.pdf

Alta Consejería para los Derechos de las Víctimas (2015). Pedagogías de la memoria, cultura y comunicación del Centro de Memoria, Paz y Reconciliación. ACDVPR.

Alvarado, M. C., Carmona-Parra, J. A. y Alvarado Salgado, S. V. (2014). Niños en contexto de conflicto armado: narrativas generativas de paz. Infancias Imágenes, 13(1), 52-60.

Alvarado, S. V., Ospina, H. F., Quintero, M. y Ospina-Alvarado, M. C. (2012). Las escuelas como territorios de paz. Construcción social del niño y la niña como sujetos políticos en contextos de conflicto armado. Clacso; Universidad de Manizales; Cinde.

Arias-Vanegas, B. E. (2016). Otras infancias, crianza y conflicto armado. En Memorias I/ Bienal Iberoamericana Infancias y Juventudes (pp. 1672-1682). Cinde; Universidad de Manizales; Clacso.

Becerra, A. J., Infante-Acevedo, R. y Cortés, R. A. (2012). Escuela, memoria y conflicto en Colombia. Un ejercicio del estado del arte en la temática. Revista Colombiana de Educación, 287-314.

Carmona-Parra, J. y Serna, I. (2018). Subjetivación política y configuración de identidades en niños y niñas y sus agentes relacionales, afectados por el conflicto armado. En M. Ospina-Alvarado, S. Alvarado, J. Carmona-Parra y A. Arroyave, Construcción social de niñas y niños en contextos de conflicto armado (pp. 167-198). Zapata.

Centro Nacional de Memoria Histórica (2016). Desde el Carare la niñez y la juventud siembra cultura de paz. Ciclo uno: grados de 2 a 5. CNMH.

Centro Nacional de Memoria Histórica (2018). Guía de acompañamiento para el cuento. Un largo camino. Bogotá: CNMH.

Centro Nacional de Memoria Histórica y Caja de Compensación Familiar Compensar (2017). Herramienta metodológica del monumento sonoro por la memoria: mi voz es tu voz, la escucho. Centro Nacional de Memoria Histórica.

CNMH (22 de agosto de 2014). Centro Nacional de Memoria Histórica. http://www.centrodememoriahistorica. gov.co/noticias/noticias-cmh/obra-teatral-para-ninos-habla-de-desaparicion-forzada

CNMH (7 de junio de 2016). Monumento sonoro: la historia de los colibríes y las langostas [Audio]. https:// soundcloud.com/memoriahistorica/sets/monumento-sonoro-la-historia-de-los-colibries-y-las-langostas

CNMH (2016). Una travesía por la memoria: ruta metodológica para la reconstrucción de memoria histórica con niños, niñas y adolescentes. Centro Nacional de Memoria Histórica.

CNMH (2017). Una guerra sin edad: informe nacional de reclutamiento y utilización de niños, niñas y adolescentes en el conflicto armado colombiano. Centro Nacional de Memoria Histórica y otros.

CNMH (noviembre de 2018). Un canto pa' no olvidar a la niñez de Colombia. Centro Nacional de Memoria Histórica.

Córdoba, Z., Riaño, D. P., Rodríguez, J., Sierra, S. y Vargas, L. (2016). Propuesta pedagógica a partir del enfoque diferencial. Me cuentan, me cuento... mi cuento. En Memorias II Bienal Iberoamericana de Niñez y Juventud (pp. 1733-1740). Cinde; Universidad de Manizales; Clacso.

De la Rosa-González, D. (2015). Érase una vez en el país del nunca más. Juego, arte y cultura para la reparación simbólica de la primera infancia víctima del conflicto armado en Bogotá. Cambios y Permanencias, 307-330.

Díaz, C. J. (2009). Fuentes vivas, memoria y pesquisas sociales a propósito de niños, niñas y jóvenes desvinculados del conflicto armado en Colombia. En A. J. Becerra y F. Guerra García, Las luchas por la memoria (pp. 219-236). Ipazud.

Errazkin, M. y Martínez, R. (2012). Trabajando con la memoria histórica en el aula. Secuencia didáctica y guía para la implementación. Sociedad de Ciencias Aranzdi.

Giraldo-Hoyos, A. (2016). ¿Cuál paz y cuál educación para la paz? Aleph, 95-100.

Gómez-Esteban, J. (2009). Voces que quieren hacerse oír (narrativas de la memoria y el olvido en la escuela). En A. J. Becerra y F. García Guerra, Las luchas por la memoria (pp. 145-157). Ipazud.

Gómez, A., Ospina, M. C., Alvarado, S. V. y Ospina, H. F. (2014). Las infancias en el conflicto armado: potencias y subjetividades políticas. En J. Martínez y O. Neyith, Pensar las infancias: realidades y 
utopías (pp. 149-169). Fundación Cultural Javeriana de Artes Gráficas (Javegraf).

Gómez, D. H. (2016). La memoria y la enseñanza de la violencia política desde estrategias audiovisuales. Revista Colombiana de Educación, 253-278.

Grasa, R., Carvajalino, G. y P., D. (2019). Construcción de paz y posconflicto: una visión general del estado del arte. En R. Grasa, G. Carvajalino y D. P., Construcción de Paz y Valor compartido (pp. 21-39). Ícono.

Gutiérrez-Rodríguez, M. J., Ortiz, M. y Muñoz-Carrasco, J. K. (2016). Interacción pedagógica con niños y niñas que participan en la construcción de paz en sus comunidades. Experiencia en la comuna tres del municipio de Chaparral. En M. C. Ospina, C. Jaime, M. Fefferman, J. Loiza, D. León, A. Arroyo y D. A. Muñoz, Memorias /I Bienal Iberoamericana de Infancias y Juventudes (pp. 1284-1291). Cinde; Universidad de Manizales; Clacso.

Jiménez-Ossa, M. y Luna-Carmona, M. (2018). Estado de la práctica sobre las experiencias de construcción de paz oriente medio de Antioquia. En M. Luna Carmo-

Jiménez-Becerra, A. e Infante Acevedo, R. (2008). Infancia y ciudad en Bogotá. Una mirada desde las narrativas populares urbanas. Universidad Distrital Francisco José de Caldas.

López-Arboleda, G. M. (2013). Los niños invisibles: una experiencia psicoeducativa infantil con los hijos de la guerra: la experiencia de Ceparcito. En A. Álvis, C. P. Duque, A. Rodríguez, M. A. Enciso y L. Ríos (eds.), Reflexiones sobre infancia (pp. 4-63). Fundación Universitaria Luis Amigó.

Manrique-Suárez, V. (2014). Derechos humanos y diversidad cultural. Conflicto, resistencia y cuerpo en niños, niñas y jóvenes. Infancia, memoria y conflicto armado en Colombia. Una mirada desde 1985 a la actualidad. En Memorias I Bienal latinoamericana de infancias y juventudes (pp. 12-20). Cinde; Universidad de Manizales; Clacso.

Medina, A. F. (2016). Autobiografía: infancia, memoria y olvido desde una perspectiva filosófica. Santiago de Chile.

Mejía, A. C. y González, G. (eds.) (2009). Colombia: huellas del conflicto en la primera infancia. Panamericana Formas e Impresos S. A.
Ministerio de Justicia de la República de Colombia (2012). Déjala volar. Ministerio de Justicia de la República de Colombia.

Montoya-Ramírez, N. y Zuluaga-Arias, L. I. (2014). Historias en colores: narrativas iconológicas e infancia. Un estudio sobre la propuesta. En, Memorias I Bienal Latinoamericana de niñez y juventud (pp. 81-90). Cinde; Universidad de Manizales; Clacso.

Naranjo-Moreno, J. (2015). Los niños piensan la paz. Banco de la República de Colombia.

Ortega, I. y Ruetti, E. (2014). La memoria del niño en la etapa preescolar. Anuario de Investigaciones, 21, 267-276.

Ospina, M. C., Jaime, C., Fefferman, M., Loiza, J., León, D., Arroyo, A. y Muñoz, D. A. (2016). Memorias II Bienal Iberoamerica de Infancias y Juventudes. Eje 4. Cinde; Universidad de Manizales; Clacso.

Ospina-Alvarado, M. (2018). Construcción social de niñas y niños: familias, docentes y otros agentes relacionales. Universidad Pedagógica Nacional; Cinde; Universidad de Manizales.

Ospina-Alvarado, M. C., Alvarado, S. V. y Ospina, H. F. (2013). Construcción social de la infancia en contextos de conflicto. En V. Llobet (ed.), Pensar la infancia desde América Latina: un estado de la cuestión (pp. 35-60). Clacso.

Ospina-Alvarado, M., Alvarado, S., Ospina, H., Pineda, M., Fajardo, M., Urrego, A. y Sánchez, M. (2018). Procesos de construcción de paz, democracia y reconciliación con niñas y niños en contextos de conflicto armado. En M. Ospina-Alvarado, S. Alvarado, J. Carmona Parra y A. Arroyo (eds.), Construcción social de niñas y niños en contextos de conflicto armado (pp. 199-247). Zapata.

Ospina-Alvarado, M., Carmona-Parra, J. y Alvarado-Salgado, S. (2014). Niños en contexto de conflicto armado: narrativas generativas de paz. Infancias Imágenes, 13(1), 52-60.

Ospina-Ramírez, D. A. y Ospina-Alvarado, M. C. (2017). Futuros posibles, el potencial creativo de niñas y niños para la construcción de paz. Latinoamericana de Ciencias Sociales, Niñez y Juventud, 175-192.

Palermo, Y. C. (2009). Memorias de juegos y juguetes: otras formas de hacer historia en la infancia. En A. J. Becerra y F. Guerra García (eds.), Las luchas por la memoria (pp. 157-179). Ipazud. 
Parra-Ospina, A. Y. (2014). Lo relacional en el arte como estrategia para la generación de narrativas en la investigación con. En, Memorias I bienal Iberoamericana de Niñez y Juventud (pp. 105-115). Cinde; Universidad de Manizales; Clacso.

Pineda-Muñoz, J. (2016). Pensando en otras maneras de la paz. Aleph, 61-66.

Quintero, M., Mateus, J. y Montaño, N. (2013). Narrativas del daño moral de niños y niñas en experiencias. En V. Llobet, Pensar la infancia desde América Latina: un estado de la cuestión (pp. 81-90). Clacso.

Ricoeur, P. (1999). La lectura del tiempo pasado, memoria y olvido. Arrecife.

Rodas, M. (2016). Voces en flor, poesía para la paz. Zapata.

Rodríguez-Bustamante, A., López-Arboleda, G. y Echeverri-Álvarez, J. (2017). El aula de paz: familia y escuela en la construcción de una cultura de paz en Colombia. Perseitas, 206-223.

Salazar-Castilla, M., Jaramillo-Ferro, J., Aristizabal-Ramírez, E. y Carmona-Toro, P. (2018). Primer Informe Línea de Paz. Construcción territorial de la Paz: polifonías y resistencias desde la ciudad de Manizales. Universidad Católica de Manizales.

Sarmiento-Álvarez, B. X. (2015). Niñez, desplazamiento forzado interno y memoria histórica (segunda parte). En B. X. Sarmiento Álvarez y M. Gutiérrez Quevedo (eds.), Cátedra Unesco. Derechos Humanos y Violencia: Gobierno y Gobernanza (pp. 149-174). Universidad del Externado de Colombia.

UNHCR (2013). Te cuento ni cuento. Acnur.

Valderrama, C. E. (2001). Nociones del conflicto en actores escolares. Nómadas, 76-87.

Vallejo-Franco, B. E. (2018). Un largo camino. CNMH. 